structure. This aspect was illustrated by a model, at present being tested, of the spillway for the Sasuma Dam in Nairobi.

Models of the cooling-water intakes for the Sizewell nuclear power station were also on show. One, an air model, was being used to determine the head losses at the junctions between the intake shafts and tunnels. As a result of the tests made on this model, modifications to the hydraulic design which naturally had to be compatible with the structural engineering requirements have reduced the head losses due to the junctions by 40 per cent.

The diversity of interests of the Association was of advantage in this case, as the modifications were based on experience gained previously in the study of ventilation schemes of mines. These intakes will be located in a tidal estuary, and a water model has been constructed to examine the effects of tidal flow and tide-level on the flow and head loss in the intakes, and the possibilities of the formation of air entraining vortices.

The Association is also active in the rapidly expanding field of 'industrial hydraulics'. There are many problems involved in the design and utilization of high-pressure oil hydraulic machinery, and a particular example is the use of slipper pads to transmit the thrust from a swash plate to the pistons in an axial-piston pump. An analysis of the conditions for minimum power consumption of these slipper bearings has shown that the minimum occurs when the viscous drag loss is three times as large as the flow loss, although this ideal cannot always be attained as the resulting film gap would be too small. A new apparatus has been built to test slipper bearings under dynamic conditions.

Examples of machines embodying design features of this nature were seen in the form of two experimental power transmissions. One is for applications which require a rapidly variable speed, and is a 2 horse-power ball-piston pump/motor machine. The extremely low inertia of this unit is demonstrated by the fact that full reversal of rotation at 3,000 r.p.m. takes about 0.01 sec. The second exhibit was designed for a motor-vehicle drive where a prime requirement is high efficiency. This unit employs a differentially coupled pump and motor and has an efficiency exceeding 90 per cent, over a wide range of speod.

The Association has been active in work to ensure compatibility between a hydraulic system, and the hydraulic fluid. A rig was demonstrated for the evaluation of hydraulic brake fluids to study, over a wide range of temperatures, such factors as brake response, leakage, seal life and fluid deterioration. A committee has recently been formed to draw up a specification which will define adequately the properties required of a fluid to be used in particular applications.

Recently, the efforts of the Association in research on fluid sealing have been increased considerably by special contributions from members. This research is directed towards studying the physical processes involved in sealing in mechanical seals, stuffing boxes, and reciprocating shaft seals. A new test rig has been built to study the behaviour of mochanical seals at pressures up to 3,000 p.s.i. In particular, the rig will be used to investigate the possibility that the present limits on the pressure rating of this type of seal are due to mechanical distortion.

In reciprocating-shaft seals it has been found that the leakage is proportional to the square of the shaft speed, and independent of pressures above 1,000 p.s.i. The leakage increases and the friction decreases as the fluid viscosity is increased.

Although the exhibition was primarily of the present research work, an equally important function of the Association is to assist members in the solution of day-to-day problems involving fluid flow, and in issuing an Abstract Bulletin and technical reports which keep the membership in touch with the work carried out in other laboratories.

A problem common to all research associations is that of ensuring that the designers and development engineers, who will benefit most from the experience available at the laboratory, are kept informed of the service which is available. To this end, a mobile unit has been fitted out with exhibits demonstrating all the aspects of the work of the Association. The visits made so far by the unit, to member firms, have resulted in a fruitful interchange of ideas between the research staff of the Association and their colleagues in industry. $\quad \mathrm{S}$. T. BonNINGroN

\title{
BLOOD GROUPS OF ANIMALS OTHER THAN MAN
}

\begin{abstract}
A CONFERENCE on "Blood Groups in Infrahuman Species", organized by the New York Academy of Sciences, was held in New York during May 15-16. The programme of papers arranged by Drs. D. B. Amos and C. Choen very fully covered much present-day research on the identification of blood groups in animals other than man, and their use in a variety of pure and applied sciences. On the first day several papers described work with animals useful in medical research. Drs. R. D. Owen (California Institute of Technology) and D. R. Anderson (School of Aviation Medicine, Brooks Air Force Base, Texas) had collaborated on a study of blood groups in the rhesus monkey, with the object of providing markers for transplanted erythropoietic tissue in irradiated animals. Blood group systems in the dog had been thoroughly investigated by
\end{abstract}

Drs. S. N. Swisher, L. E. Young and N. Trabold (Rochester School of Medicine, N.Y.), and used in experimentation of elinical interest. The rabbit is valuable in comparative research on hæmolytic disease of the new-born, and for this a knowledge of its blood groups was an essential pre-requisite. Dr. C. Cohen (Battelle Memorial Institute, Columbus, Ohio) pointed this out in his review paper, while making an eloquent plea for research workers to co-operate more closely in establishing nomenclature of blood group systems. Dr. Cohen also provided an illustration of the wider interest of the conference with his discussion of genetical aspects and natural selection. The usefulness of rats as laboratory animals was exemplified by the inclusion of three papers about them. Dr. R. D. Owen reported on genetic systems of antigens which had proved abun- 
dantly useful as tools in a variety of experimental studies, in particular of red cell chimærism following either parabiosis, embryonic injection or bone marrow injection after $\mathrm{X}$-irradiation. The interest of Drs. A. E. Bogden and P. M. Aptekmen (Biochemical Research Foundation, Newark, Delaware) was in inherited hæmagglutinogens of rats and their relationship to histocompatability factors. The presence or absence of one hrmagglutinogen determined growth or rejection of a tumour, and this system showed a number of other interesting parallels with the $H$-2 factors of mice. In a careful review paper, Dr. J. Palm (Wistar Institute, Philadelphia), described her own work with blood groups and histocompatibility factors of rats and related it to that of other investigators.

The first of three papers on mice was a review by Dr. D. B. Amos (Roswell Park Memorial Institute, Buffalo) in which most emphasis was naturally enough placed on the classical $H-2$ system of tissue and red cell antigens. A clear account of the serological and genetical complexity of this system was given. Drs. R. Basch and C. A. Stetson (Bellevue Medical Center, New York) followed with a description of results obtained using an assay method for those antigens of mice which elicit cytotoxin and hæmagglutinin production (antigens which they believe to be absolutely identical). A wide range of isoantigen activity - as judged by ability to absorb or neutralize cytotoxins-was found among various mouse tissues. Further detailed chemical results included the important finding that in liver homogenates antigenic activity was concentrated in the lysosome-rich fraction. Finally with mice, Dr. J. W. Goodman (Oak Ridge National Laboratory) described experiments in which blood or bone marrow, or both, were injected into irradiated mice, and the fate or estab. lishment of the donor-type cells followed by serological means, either hæmolytic, for red cells, or cytotoxic, for lymphoid cells.

The remainder of the papers on the first day were of more general zoological interest, rather than specifically medical. Dr. J. Buettner-Janusch (Department of Anthropology, Yale) had studied the reactions of the red cells of various primates with various antisera prepared to agglutinate human $A$ or $B$ red cells. This work was intended primarily as an aid to anthropological investigations. In connexion with an entirely different sort of population study Dr. G. F. Ridgway (U.S. Bureau of Fisheries, Seattle) gave a fascinating account of the extremely difficult work involved in analysing blood groups of salmon and trout, primarily using isoimmunizations. Dr. W. H. Hildemann (University of California at Los Angeles) interpreted the term 'blood groups' in its very widest sense in considering the literature and his own work on genetic specificities of amphibians and reptiles. Individual differences in red cell antigens have been found in only five species; no intraspecific differences in serum proteins-as determined electrophoretically-have yet been found, although their existence as raw material for speciation must be postulated, in view of the known ordinal, familial or interspecific differences. In contrast to the above sparse evidence of diversity, tissue transplantation studies yielded evidence of a high degree of intraspecific antigenic diversity. The role of individual red cell antigens in speciation has of course been the main theme of the classical researches of Dr. M. R. Irwin et al. on pigeons and doves, and an authoritative account of this work was presented by
Dr. D. H. Shaw (University of Wisconsin, Madison). Other aspects mentioned included the study of hybrid substances, and the use of blood-group factors as markers in somatic mutation work and in radiation chimæra research (the latter being Dr. Shaw's own particular contribution). The final paper on the first day was introduced humorously by the chairman as being about blood groups of bacteria. Dr. G. F. Springer (University of Pennsylvania, Philadelphia) had continued his previous work on the immune origin of so-called natural anti-human $B$ antibodies -in which 'germ-free' chicks were inoculated with $E$. coli $O_{86}$-by studying the chemistry of the bacterial substances responsible for the cross-reactivity. Among various findings were striking resemblances to human blood group substances, as shown by the composition of the carbohydrates produced by hydrolysis.

The second day's programme was devoted almost entirely to blood-groups of animals of agricultural interest. The first of four papers on chickens was a general survey by Dr. D. G. Gilmour (School of Agriculture, Cambridge, England). One point especially emphasized was that the chicken has particular advantages as an experimental animal for the study of selective factors influencing the polymorphism of blood groups. Considerable evidence on this aspect was already available. Dr. W. E. Briles (De Kalb Agricultural Association, De Kalb, Illinois) followed with a meticulous account of experimental techniques leading to the discovery of further blood group systems in chickens, of which six were described, five probably new. Evidence on the relationship between $B$ locus blood group genotypes of female parents, and the economic performance of their 'hybrid' offspring (four-way crosses of inbred lines), was presented by C. P. Allen (Hy-Line Poultry Farms, Johnston, Iowa). This paper was especially interesting, being indicative of the possibility of the application of blood groups in some systems of commercial poultry breeding. Work on a red cell agglutinogen of chickens identified by certain plant seed extracts was described by Drs. S. L. Scheinberg and R. P. Reckel (U.S. Department of Agriculture, Beltsville). The occurrence of this factor is both inherited and influenced by hormonal state, occurring in genetically competent females only on the onset of egg-laying. Pigs were the subject of two papers, the first being a very clear account of the state of knowledge of their blood groups by Dr. E. Andresen (Iowa State University, Ames), much of whose own work had been done at the Royal Veterinary and Agricultural College, Copenhagen. His interest was primarily in genetic studies, and to a lesser degree in hæmolytic disease of the new-born. This condition was the prime interest in the second paper on pigs by Drs. $R$. Saison and D. G. Ingram (Ontario Agricultural College, Guelph), who reported on some systems previously described, and other new ones. They also briefly mentioned studies of blood groups of mink.

The report on horse blood groups by Dr. D. Franks (Department of Pathology, Cambridge, England) was largely concerned with hæmolytic disease of the new-born foal, and included much important material of veterinary and comparative medical interest. Dr. Franks's suggested interpretation of some of his serological findings-variation in amount of antigens in different genotypes - as being due to a cis-trans position effect provoked one of the most lively discussions of the meeting.

The last afternoon session was opened by Dr. C. Stormont (University of California at Davis), who 
presented a highly competent and scholarly review of blood groups in cattle. In one cattle system, $J$, the antigenic substance is found in soluble form in various body fluids and tissues, and is absorbed on the red cells. This was the subject of a contribution by Dr. W. H. Stone (University of Wisconsin, Madison), who discussed physiological, genetical and chemical aspects. Dr. J. Gasparski (Polish Academy of Science) was unfortunately unable to attend the meeting, and his paper-on red cell antigens of the European bison identified by cattle blood typing reagents - was read for him. A definitive account of blood-group systems of sheep was given by Dr. B. A. Rasmusen (University of Illinois, Urbana), and the meeting concluded with a fascinating account, presented by Dr. A. Eyquem (Pasteur Institute, Paris), of blood group investigations by himself and Drs. L. Podliachouk and P. Millot. Species involved were chimpanzees, horses, mules, donkeys, sheep, pigs and cattle.
The papers described above are to be published as soon as possible in the Annals of the New York Academy of Sciences, and should remain definitive for some time to come. In addition, the meeting provided an excellent opportunity for exchange of opinions between workers in widely diverse fields, and there can have been few attending who did, not acquire ideas for new approaches. Discussions were especially enlivened by the presence of some guests noted particularly for their research on human blood groups, among whom may be especially mentioned Drs. W. C. Boyd, S. D. Lawler, P. A. Levine and A. S. Wiener. Other activities associated with the meeting included. an evening discussion meeting, which resolved to form an Immunogenetics Society of America, another evening discussion on blood-group nomenclature, and a most enjoyable dinner in honour of Dr. M. R. Irwin, arranged by some of his past students.

D. G. Gilmour

\section{DESIGN AND USE OF RESPIRATORS}

A JOINT meeting of the Ergonomies Research Society and the British Occupational Hygiene Society at Porton on July 5 and 6 was devoted to the study of respirators. The Societies were welcomed by Dr. E. A. Perren, director of the Chemical Defence Experimental Establishment (C.D.E.E.). The first paper, by C. G. Trotman (C.D.E.E.), dealt with the history of the subject. Dust masks were much the oldest form of respirator but were not really significant until a performance standard for industrial dusts was established in 1933. Canister respirators for protection against industrial gases grew from the chlorine box respirator of the First World War. The Chemical Works Regulations of 1922 enforced the provision of respirators of an adequate standard; since then, systems of coding and testing respirators for practically all known industrial and agricultural hazards have been laid down.

R. G. Dorman (C.D.E.E.) discussed fibrous filters for protection against aerosol particles. Sizes near $0.3 u$ diameter are the most difficult to filter; collisions with filter fibres are less probable for particles having low inertia and small Brownian motion so that they tend to penetrate the filter relatively easily. Experimental demonstration of a minimum of filtration efficiency at a certain particle size proved the general validity of the theory of filter action. The resin-wool filter was described, which combined extremely low air-flow resistance with high efficiency, due to electrostatic action. Methylene blue and sodium aerosol testing, with flame photometer detection, were also discussed, and desirable standards of protection indicated.

F. A. P. Maggs (C.D.E.E.) gave an account of the removal of gases by activated charcoal. Adsorption is a matter of the surface area of the charcoal and the number of molecules of gas, so that a high molecular-weight gas is retained better than one having small molecules. The life-time of a respirator against volatile, low-molecular-weight vapours may be quite short and there is some difficulty about giving proper warning of incipient failure to the user.

J. E. Cotes (Medical Research Council Pneumoconiosis Research Unit) dealt with physiological aspects of respirator design, including breathing apparatus supplied with oxygen. Factors of impor- tance included dead space, flow-resistance, vision, fit of face-piece, and leakage. In addition to protecting the wearer, breathing sets with closed circuit made it possible to help him in situations involving physiological stress by humidifying, cooling and adding oxygen to the air which he breathed.

The ergonomics of the respirator was dealt with by R. J. Shephard (C.D.E.E.), who described methods of assessing the loss of performance resulting from wearing respirators. Deterioration of specific functions was slight, and the expenditure of energy occasioned by dead space and resistance only amounted to a few per cent of maximum effort under average conditions. General discomfort, sweating and unusual activity, however, reduced tolerance unless the subject were adequately motivated.

The work of ventilation was analysed by E. A. Cooper (Department of Anæsthesia, Newcastle upon Tyne), who directed attention to the contrasting resistance laws which were relevant to laminar flow in filter beds and turbulent flow in pipes and valves; the latter rises much more rapidly with an increase in the velocity of breathing. By considering the mechanism of respiration and cardiorespiratory function it was possible to lay down allowable standards of resistance.

Respirators, besides being protective devices, have been used in physiological research since the days of Lavoisier. H. S. Wolff (Medical Research Council, Hampstead) dealt with such applications. Mouthpieces were often used in place of masks, for brief experiments, but were uncomfortable and promoted salivation. Masks were important for measuring expenditure of energy from consumption of oxygen; types produced for anæsthetics, for airmen and for gas-masks were commonly adapted for physiological research, and various measuring devices could be attached to them.

Communication between persons wearing breathing equipment was the subject of a paper by J. Ernsting and J. E. Gabb (Royal Air Force Institute of Aviation Medicine). The situation is complicated in aircraft by the effects of reduced pressure on auditory acuity. Speech gives rise to respiratory flow patterns which impose a severe strain on the flow capacity of respiratory equipment. 